\section{AN UNUSUAL MUSHROOM OF REGINA AND TRISTAN DA CUNHA}

FRANK BRAZIER, 2657 Cameron Street, Regina, Saskatchewan.

Tristan da Cunha is a group of three small islands in the south Atlantic Ocean, belonging to Great Britain, and situated in latitude $37^{\circ} 06^{\prime} S_{\text {., }}$ and longitude $12^{\circ} 01^{\prime} \mathrm{W}$, about equidistant from South Africa and South America. The islands are named Tristan, Nightingale and Inaccessible, and are peaks of submerged mountains of the Mid-Atlantic Ridge. On my desk globe the islands are, roughly, 6,700 miles from Regina, as the American Crow flies but none of our Crows make such a lengthy journey in one trip. Remote as Tristan da Cunha is from my doorstep there is, to my mind, a connection albeit a tenuous one.

On 21 June 1984 I noticed some strange mushrooms growing among the Lilies of the Valley under my front window. Although I have a slight acquaintance with the world of fungi I knew I had never seen these before.

However, Robert Kreba, of the Saskatchewan Museum of Natural History, has studied mushrooms for years, and a telephone call brought him over on his way home. He did not recognise the mushrooms so he gathered two mature specimens and a couple in the button stage. The Museum collection contained a specimen of the same species which Bob had collected at Ille a la Crosse a few years ago but which he had not seen since. The mushrooms were Agrocybe praecox.

A search of some fungi literature disclosed that is of the Order Agricales, Family Bobitiaceae, Genus Agrocybe; some years ago it was known as Pholiata praecox (Pers.) Fr.
Their common name is Early Agrocybe, and they are described as edible. They usually appear following good rains in May and June. Regina had been blessed with heavy rains after a dry spring and practically snowless winter previous to my discovery.

Bob Kreba has been a mycophilatelist (he collects postage stamps showing mushrooms) for some time and, as an interesting footnote to the discovery of Early Agrocybe in Regina he showed me a postage stamp from Tristan da Cunha, value 10 pence, issued in 1984, depicting Agrocybe praecox, but of the variety cutifracta, indicating that the skin cracks when mature as our species does not.

The Encyclopedia of Mushrooms by Colin Dickinson and John Lucas (Orbis Publishing, London, 1979 - out of print) gives the common European name of Spring Agaric to this mushroom, and describes its range as: "common in Europe, northeastern North America and South Africa, and cautions that the caps only are to be eaten. So my doorstep mushroom had not only colonized a remote speck in the south Atlantic Ocean but was also pushing at its western limits in Canada. Such is the romance of natural history!

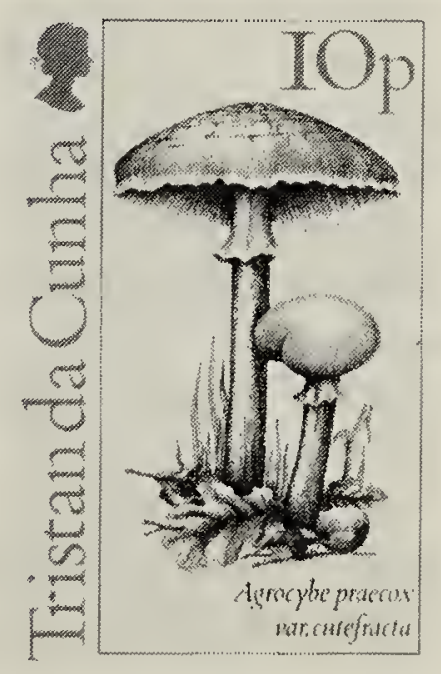

Tristan da Cunha stamp 